\author{
Military Technical College \\ Kobry El-Kobbah, \\ Cairo, Egypt.
}

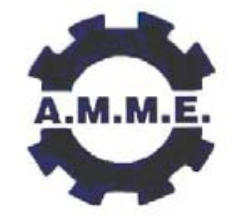

$13^{\text {th }}$ International Conference on Applied Mechanics and Mechanical Engineering.

\title{
COMPRESSOR PERFORMANCE ADAPTATION FOR GAS PATH ANALYSIS AND DIAGNOSTICS
}

\author{
SALAMAT* R.
}

\begin{abstract}
The importance of reliable engine diagnosis cannot be over emphasized as large revenues are lost due to unplanned shut downs or unnecessary scheduled maintenances. An accurate simulation model must be set up in order to minimize the errors in performance predictions and diagnostics analysis.
\end{abstract}

The objective of the proceeding works is to have a compressor performance simulation model matching the actual site data by a novel method and a model that can be reliably used for performance predictions and diagnostics. In the adaptation process, Scaling Factors (SF) are introduced and then applied to modify the compressor maps. Linear adaptation is applied to single test point while non-linear adaptation is applied to multiple test points. Three site real base cases are available and have been analyzed and evaluated, at $99.6 \%, 93.0 \%$ and $90 \%$ RPM.

Predictions of compressor performance are compared with the manufacturer's fleet maps. The prediction accuracy has been improved significantly after the adaptation. Moreover, the proposed adaptation approach could be applied for most situations.

\section{KEY WORDS}

Compressor, diagnostics, performance adaptation, site data, simulation, Compressor Non-Dimensional Flow

\footnotetext{
* PhD Researcher, Dept of Power and Propulsion, School of Engineering, Cranfield University, UK, employed at Qatar Petroleum.
} 


\section{INTRODUCTION}

During the past several decades, tremendous effort has been made to make the engine performance simulation more efficient and accurate using thermodynamic computer software [3, 4] as the application of such software can significantly reduce operating and maintenance costs.

The objective and focus of the present paper is to have a compressor performance simulation model matching the actual site data and a model that can be reliably used for performance predictions and diagnostics.

Correct diagnostics on a compressor or gas turbine depend on accurate engine performance model. An accurate engine model may be produced by selecting a best set of design point parameters and the next step is to adapt the model to satisfy engine off design performance by creating new engine component maps. Relevant techniques have been published by Li et al [1] and others. The difference between the actual compressor map and the default compressor map may be so large that the off design performance prediction error may become unacceptable for gas path diagnostics.

To reduce the off design performance prediction errors the speed lines on the manufacturer's compressor maps need to be adapted or relocated by using observed off design performance measurements. The manufacturer supplied curves are based on certain inlet/outlet parameters which may change during operation and hence the need for adaptation. In this study the measurable parameters were inlet and outlet temperatures and pressures, compressor inlet flow rates and compressor RPM. The proceeding works describes the test and compressor data as supplied by OEM (Originally Engineered by Manufacturer) followed by setting the basic theory and method of adaptation. This section is then followed by the detailed application of the proposed adaptation theory, results and conclusions.

\section{COMPRESSOR AND TEST DATA}

\section{Test Data}

Three operating Base Cases of Site Compressor data were studied. Refer to Table 1 where the parameters at inlet and outlet of the compressor and the RPM for each base case is shown.

\section{Compressor Manufacturer Data}

The available range of predicted performance curves supplied by manufacturer were studied and the closest sets of these data to the site compressor inlet conditions were chosen to be adapted. Figure 1 and Figure 2 show the chosen performance curves as supplied by the manufacturer. The summary of rated and site performance data used for adaptation is shown in Table 2.

\section{THEORY AND METHOD OF ADAPTATION}

To obtain accurate simulation model, the following steps are applied: 
(1) Start from a supplier performance map (for a fleet compressors)

(2) Adapt the map in order to match available test data

(3) Apply HYSYS to assess simulation accuracy improvement

Figure 3 shows the default map and the adapted map generated from step (1) and step (2) above. Figure 4 illustrates three curves for one of the base cases: the performance curve as supplied by the manufacturer, the corrected curve for site RPM based on supplier curve and the curve generated by HYSYS for exact performance match between site and simulated compressor. Chart 1 demonstrates the flow diagram developed for performance adaptation.

The compressor performance can be accurately modeled and predicted by HYSYS simulation programme. HYSYS is a versatile and adaptable steady state and transient state simulation programme owned by Aspentech Technology where a variety of process and rotating equipment such as compressor can be modeled. In HYSYS two modes of curves can be input for performance evaluation: Single Curve and Multiple Curves.

For single curve, the following combinations of input will allow the operation to completely solve assuming the feed composition and temperature are known:

- Inlet Pressure and Flow rate

- Inlet Pressure and Duty

- Inlet Pressure and Outlet Pressure

- Inlet Pressure and Efficiency corresponding to the Curve type (for example - if the curve is polytropic, provide a polytropic efficiency)

If multiple curves have been installed and an operating speed is specified on the Parameters page (this is a page where the Head-Flow-Efficiency values are entered), then only the curve with the corresponding speed will be used. One can specify a speed that is different than the speed values given for the curves. For example, if curves are provided for two speeds, say $7000 \mathrm{rpm}$ and $8000 \mathrm{rpm}$, and a speed of 7400 rpm is specified, HYSYS will interpolate between the curves to obtain the and the component properties are calculated at that point. You must also provide an inlet pressure and one of flow rate, duty, outlet pressure or efficiency as explained above.

HYSYS can calculate the appropriate speed based on the input. In this case, one need to provide the feed composition, pressure and temperature as well as two of the following four variables:

- Flow rate

- Duty

- Efficiency

- Outlet Pressure

Once the necessary information is provided, the appropriate speed will be determined and the other two variables will then be calculated. 
In the current works presented in this paper multiple curves were available from OEM for a variety of compressor inlet conditions and gas properties. These are numerically presented in Table 3 and graphically shown in Figures 1 and 2.

\section{CASE STUDY - APPLICATION OF ADAPTATION}

The Polytropic head for a compressor can be shown to be given by [5]:

$$
H_{p}=\left(\frac{Z_{\text {avg }}}{1000}\right)\left(\frac{8314}{M W}\right) \times T_{\text {in }} \times\left(\frac{\mathrm{k}}{\mathrm{k}-1}\right) \times \eta_{\mathrm{p}} \times\left[\left(\mathrm{r}_{\mathrm{p}}\left(\frac{\mathrm{k}-1}{\mathrm{k}}\right)\left(\frac{1}{\eta_{\mathrm{p}}}\right)\right)-1\right]
$$

where,

$H_{p}=$ Polytropic Head, $\mathrm{kJ} / \mathrm{kg}$

$Z_{\text {avg }}=$ Gas Average Compressibility (alternatively $Z_{\text {inlet }}$ could be used if the OEM has based his performance calculations at inlet conditions)

$\mathrm{MW}=$ Inlet gas molecular weight, $\mathrm{kg} / \mathrm{kmol}$

$\mathrm{T}_{\text {in }}=$ Compressor inlet temperature, $\mathrm{K}$

$\eta_{p}=$ Polytropic efficiency

$r_{p}=$ Pressure Ratio

$\mathrm{k}=\mathrm{C}_{\mathrm{p}} / \mathrm{C}_{\mathrm{v}}$

From equation (1), $H_{p}$ varies linearly with $T_{\text {in }}$ and $Z_{\text {avg }}$ and it varies inversely with $M W$. Further, Fan laws apply well for small changes in N (the RPM of compressor) such that $H_{p}$ varies nonlinearly with $\mathrm{N}^{2}$. By comparison between $\mathrm{k}$ values supplied by OEM and site, the differences are diminishingly small to have any effect on $\mathrm{H}_{\mathrm{p}}$ values in line with ASME PTC10 where variations up to $+/-4 \%$ can be tolerated due to inaccuracy of measuring devices and design tolerance. Hence, it follows that for the purpose of adaptation, equation (1) could be modified as:

$$
\mathrm{H}_{\mathrm{p}_{-} \text {SiteRPM }}=\mathrm{H}_{\mathrm{p}_{-} \text {OEM }} \times\left(\frac{\mathrm{z}_{\text {Site }}}{\mathrm{z}_{\text {OEM }}}\right)\left(\frac{\mathrm{MW}_{\text {OEM }}}{\mathrm{MW}_{\text {Site }}}\right) \times\left(\frac{\mathrm{T}_{\text {in,Site }}}{\mathrm{T}_{\text {in, OEM }}}\right) \times\left(\frac{\mathrm{N}_{\text {Site }}}{\mathrm{N}_{\text {OEM }}}\right)^{2} \ldots .
$$

where subscripts "Site" denotes the parameters at site and "OEM" denotes the parameters as supplied by the compressor manufacturer.

The actual inlet volume flow is the best mean for plotting compressor performance curves as the impeller and therefore the compressor is sensitive only to actual volume throughput. The OEM supplied data were also based on actual volume throughput as shown in Figures 1 \& 2.

For each of the 3 Site Base Cases, equation (2) is used to obtain the expected performance of the site compressor based on the supplier performance data. HYSYS is then innovatively applied to get the exact match between site performance data and the compressor simulation model. The corresponding polytropic head and polytropic 
efficiency for exact matching is extracted from HYSYS and recorded. These values are compared with the expected performance obtained earlier and the ratio gives the scaling factor required for modifying the expected performance curve obtained earlier by equation (2). This factor gives exact match for the site flow condition. The resultant performance curves thus become the real performance curves specific to the compressor under observation and these will be used for GPA and diagnostic purposes. Table 4 demonstrates a sample for exact performance matching for site Base Case 1 Using HYSYS.

\section{RESULTS}

\section{Dependency of Expected Performance Generation on Input Data}

The new default performance maps were generated using a wide range of compressor inlet condition supplied by the manufacturer. In each case it was found the generated curves described in the preceding section hardly changed; the average difference was $0.46 \%$ for the RPM of $99.6 \%$ with a variance of 0.48 and $-0.8 \%$ with a variance of -0.32 for the RPM of $90 \%$. Refer to Figure 5 to demonstrate this result.

\section{Site Compressor Performance Curves}

Figures 6 and 7 show the derived site compressor real performance curves for Polytropic Head and Polytropic Efficiency by Adaptation using HYSYS for the 3 base cases of $99.6 \%, 93 \%$ and $90 \%$ RPMs. Under site conditions the curves provide exact solution.

Table 5 lists a comparison of parameters between the Expected and Site Performance and the errors between values before the adaptation and site measured values. Table 6 demonstrates the comparison of parameters between Measured and Site Performance Before and After Adaptation Using HYSYS. The latter table shows how the Objective Function [1, 3] or errors are reduced to minimum possible values. To expand the application of the proposed method for any compressor inlet temperature and pressure, Table 7 is derived from HYSYS to calculate the compressor non-dimensional flow (CNDF) [2] and Figure 8 shows the Pressure Ratio versus CNDF for further diagnostic purposes.

\section{CONCLUSIONS}

- The default performance maps for performance predictions given by manufacturer are generic and may apply to a fleet of compressors within the same category, i.e., the supplied data is not specific to the site compressor

- The corrected default maps show dependence on RPM and strong independence from the variation in inlet gas conditions assumed by the manufacturer. It is deduced that the corrected default maps are not inlet case dependant and even a limited supply of manufacturer supplied performance curves will suffice the objective of default map correction

- HYSYS is innovatively applied for performance matching and it has the ability to reduce the Objective Function down to its minimum value 
- The adaptation approach in this study are valid and applicable for most situations. For a given RPM, only the extremely small or extremely large flow may not be applicable since in these regions the efficiencies drops very rapidly and erratically.

- The performance curves specific to the site compressor and non-dimensional flows have been generated in this work and may be used in future diagnostics

- The advantage of proposed method of adaptation is its exact solution with minimum objective function.

- The presented works and results may be used a basis for developing the dimensionless or quasi-dimensionless parameter groups rigorously defining and predicting the engine performance

\section{REFERENCES}

[1] Li Y., Pilidis P. and Newby, M., "An Adaptation Approach for Gas Turbine Design Point Performance Simulation", J. of Eng. for G/T and Power, pp. 789-795 (2006).

[2] Walsh P. P. and Fletcher P., "Gas Turbine Performance", Blackwell Science, Oxford, Chapters 3-7, (2004)

[3] Gatto E., Li Y. G. and Pilidis P., "Gas Turbine off Design Performance Adaptation Using a Genetic Algorithm", Proc. of ASME Turbo Expo 2006, Barcelona, pp. 1-10 (2006)

[4] Alexiou A. and Mathioudakis K., "Gas Turbine Engine Performance Model Applications Using An Object Oriented Simulation Tool", ASME Turbo Expo 2006, Barcelona, GT2006-90339, (2006)

[5] Lapina R., "Estimating Centrifugal Compressor Performance", Volume 1, Gulf Publishing Co., Chapters 2 -4, (1982)

[6] Saravanamuttoo HIH, "Gas Turbine Theory", Prentice Hall, Chapter 4, $5^{\text {th }}$ edition, (2001) 


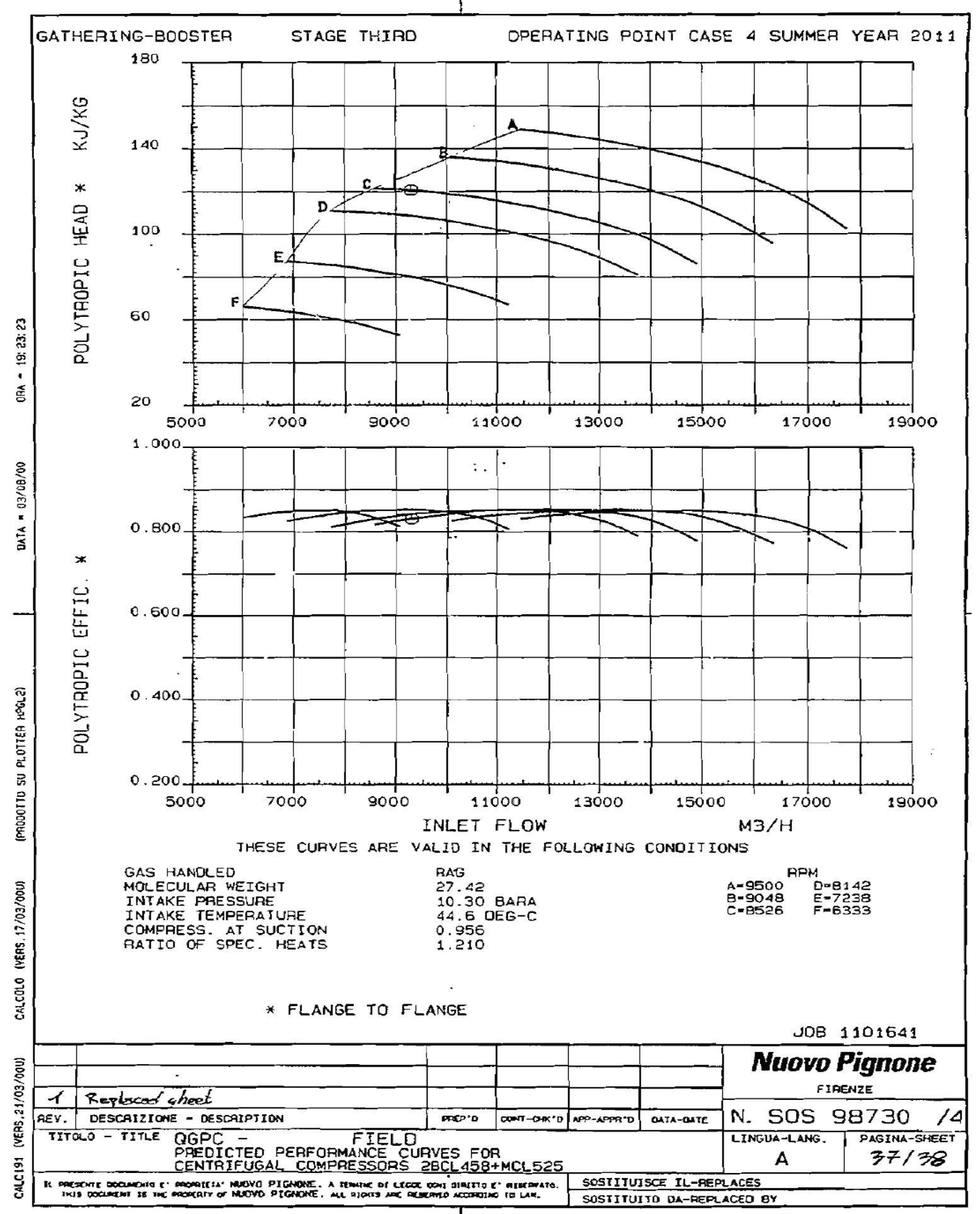

Figure 1. The adapted compressor performance curves for analysis for Base Case 1 


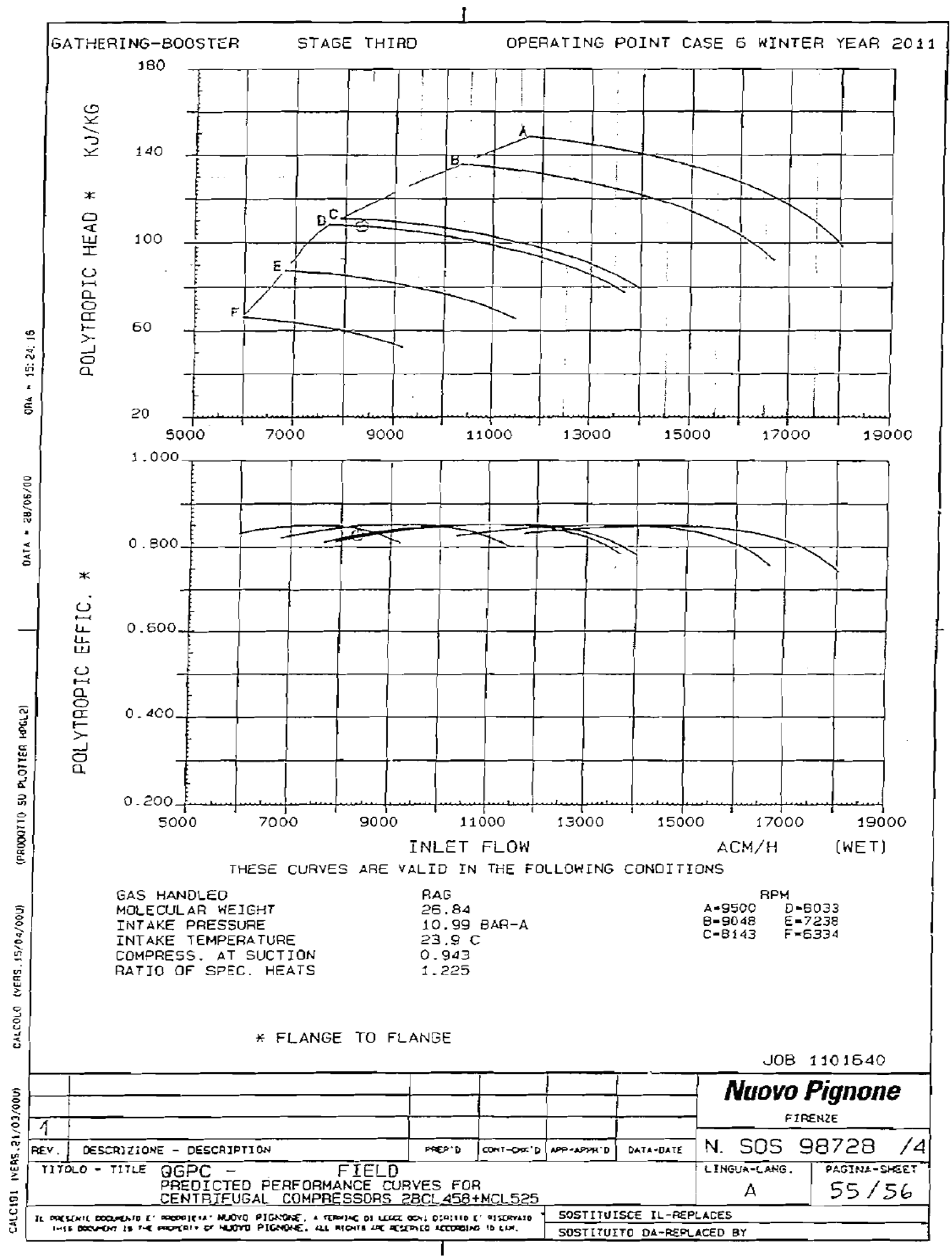

Figure 2. The adapted compressor performance curves for analysis for Base Case 2 and 3 
Polytropic Head

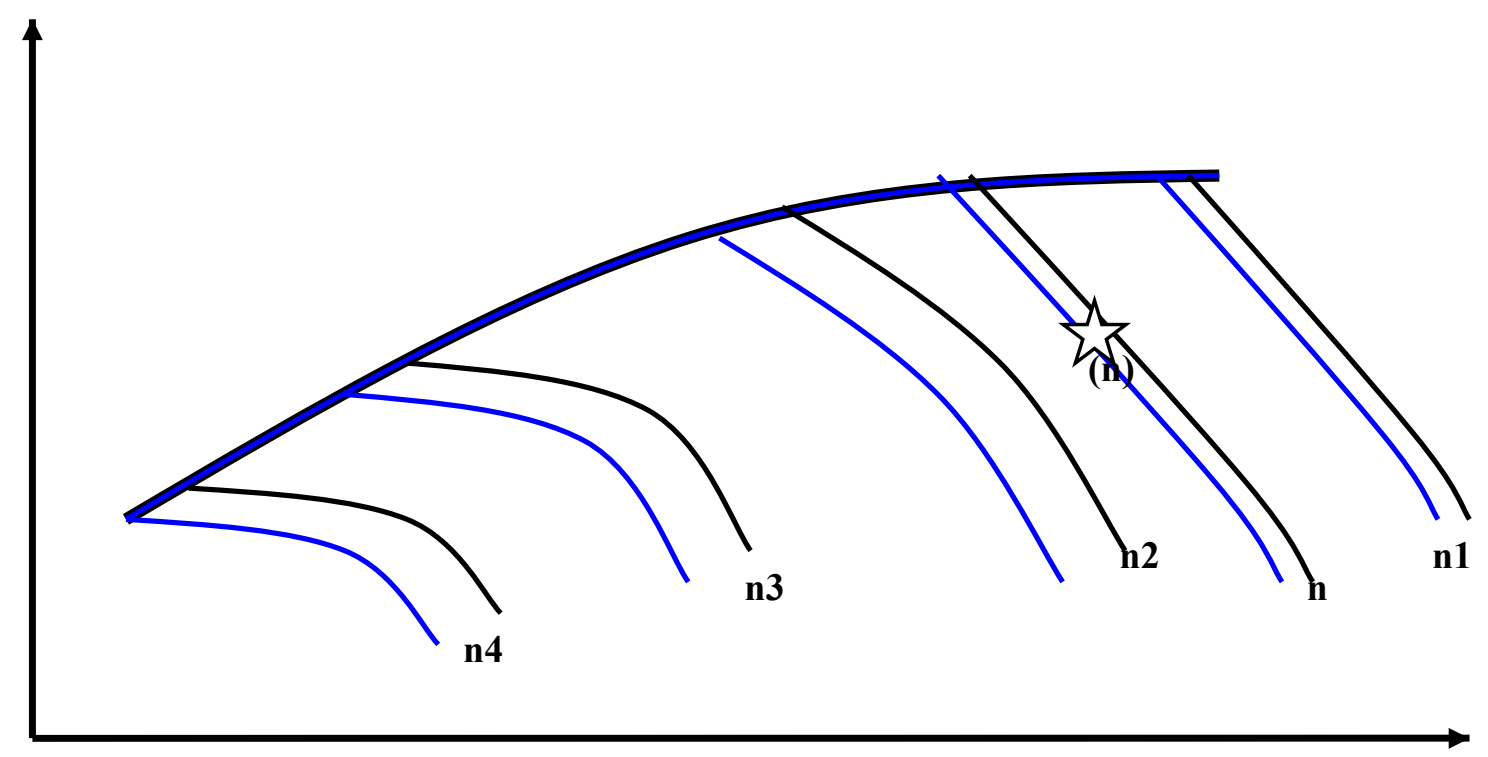

Inlet Flow Rate

Figure 3. A general compressor performance map showing the default and the adapted curves. * denotes test point. The grey map is the default map (step 1 of theory) while the blue map is the adapted map (step 2 of theory). The adapted map is further treated by HYSYS to improve accuracy.

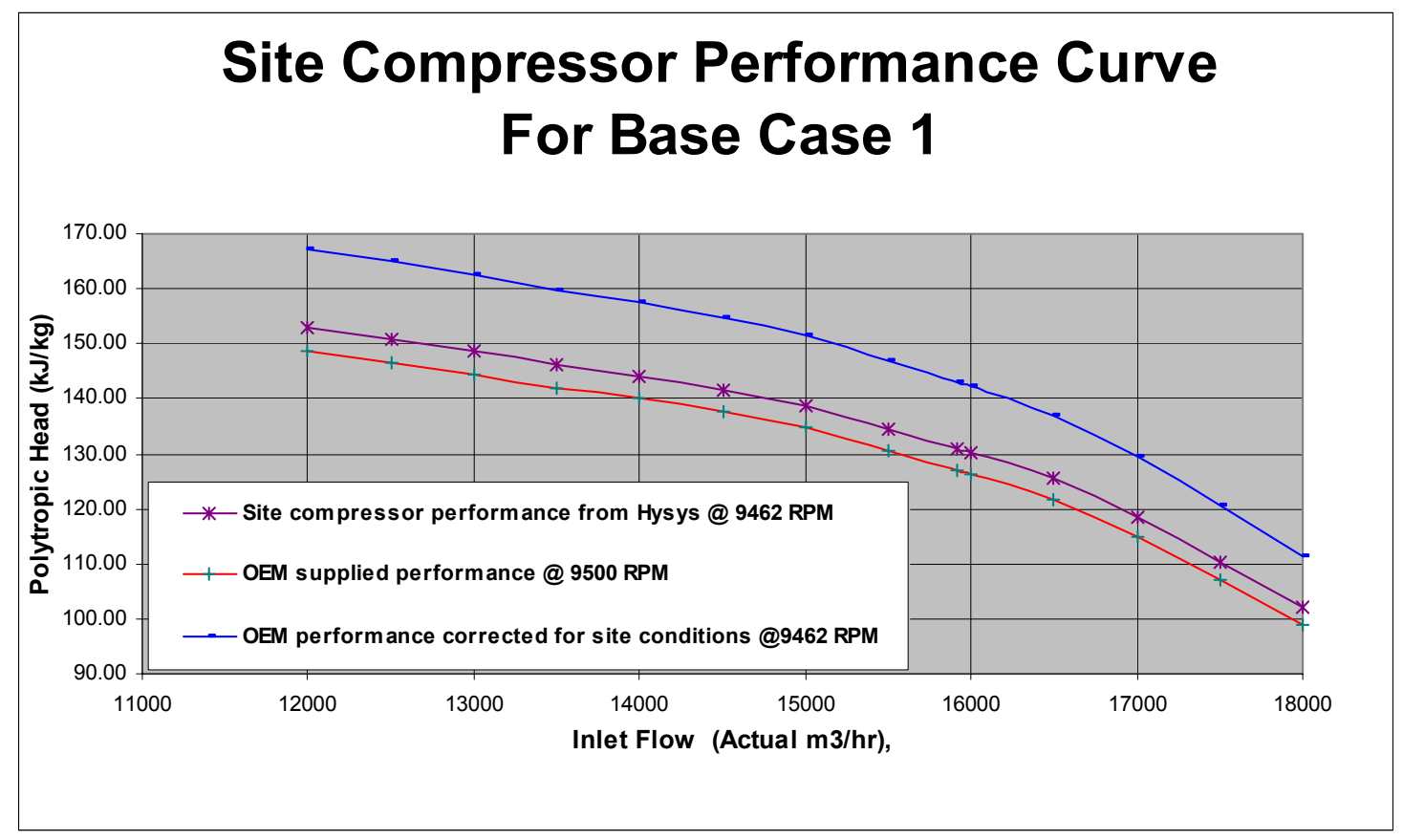

Figure 4. Superimposition of performance curve from OEM, adapted curve and the curve from HYSYS for one of the three site base cases. 


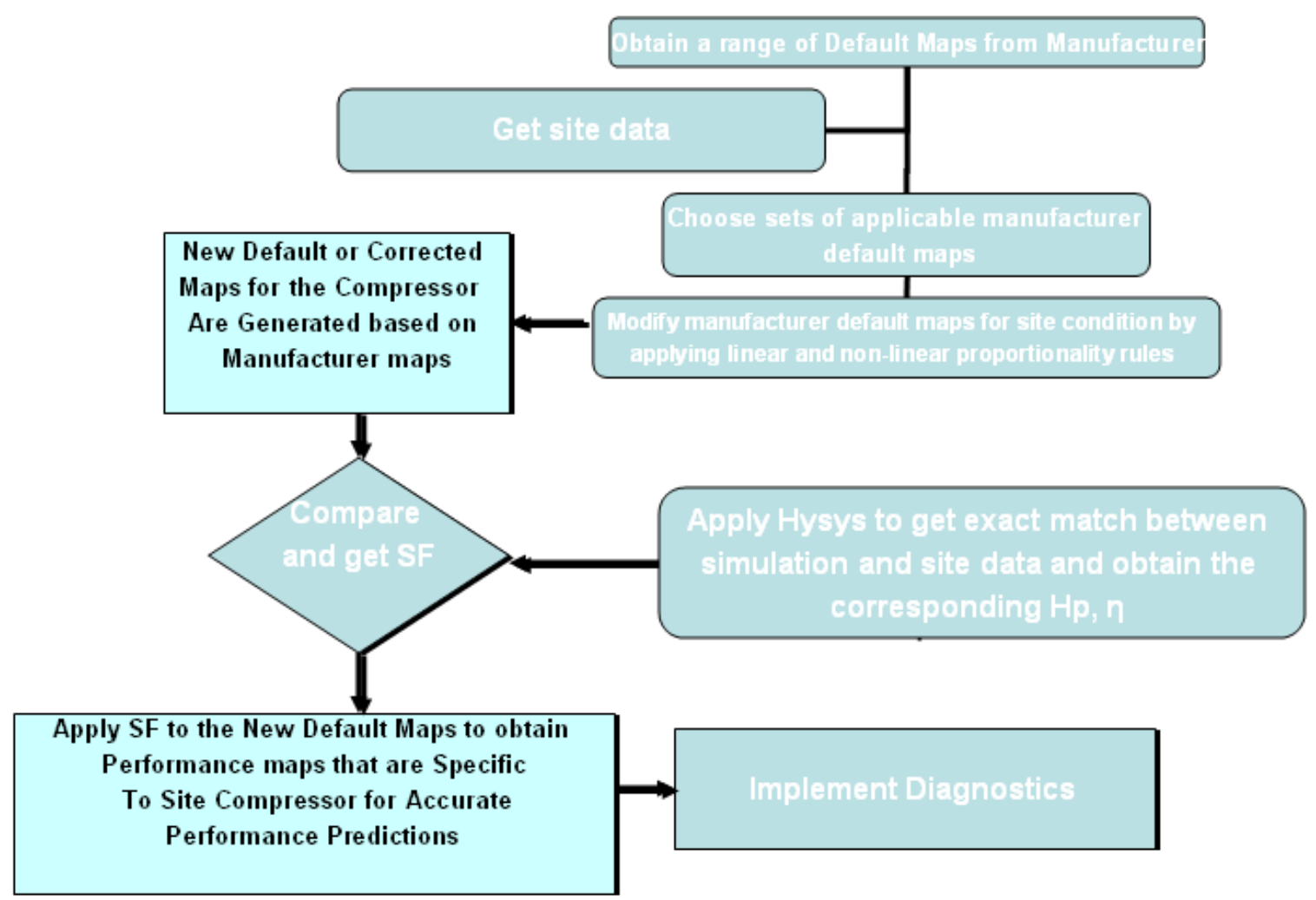

Chart 1. Flowchart for Compressor Performance Adaptation

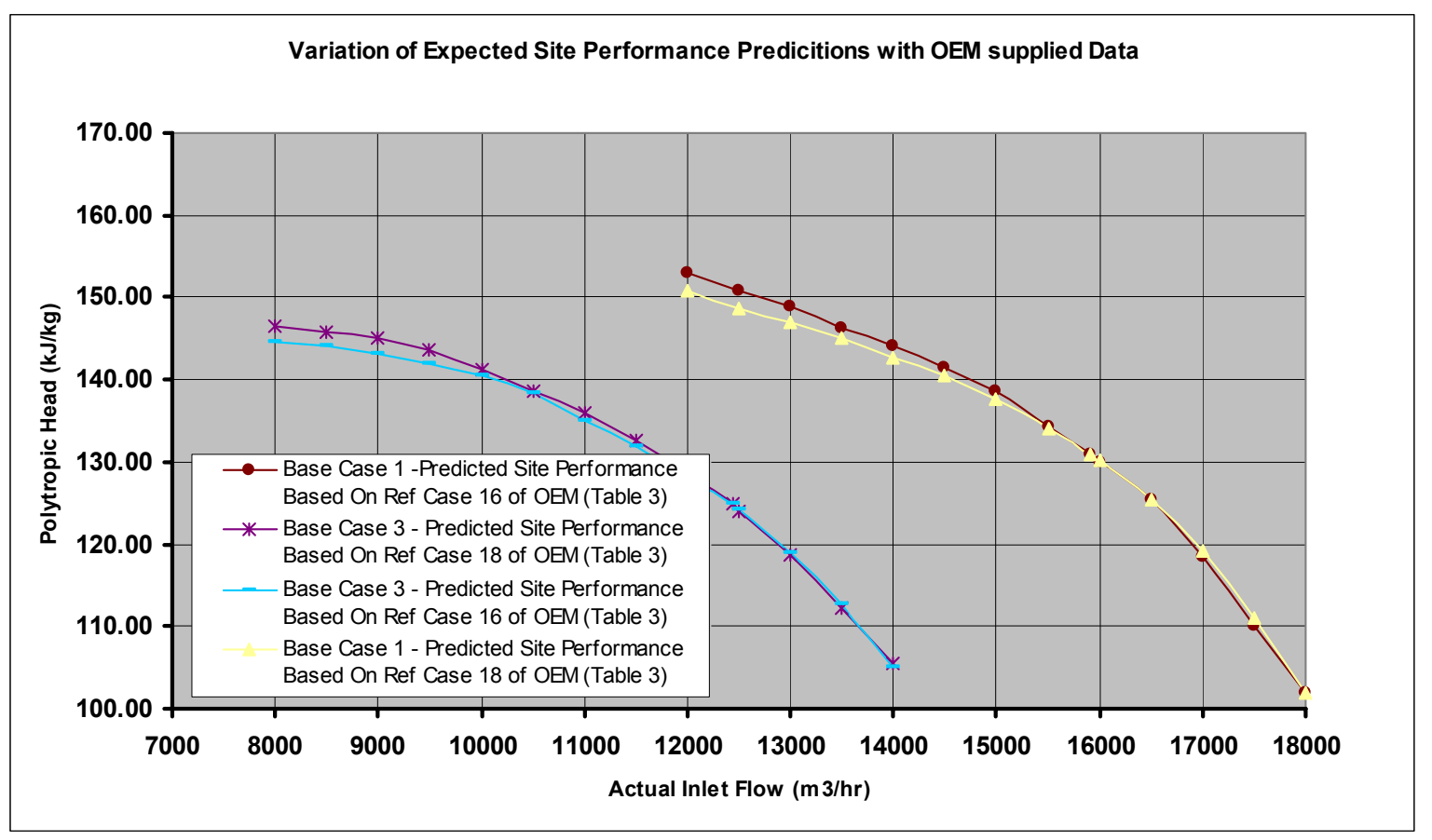

Figure 5. Dependency of expected performance calculation on input data. The overlaps show very little dependency 


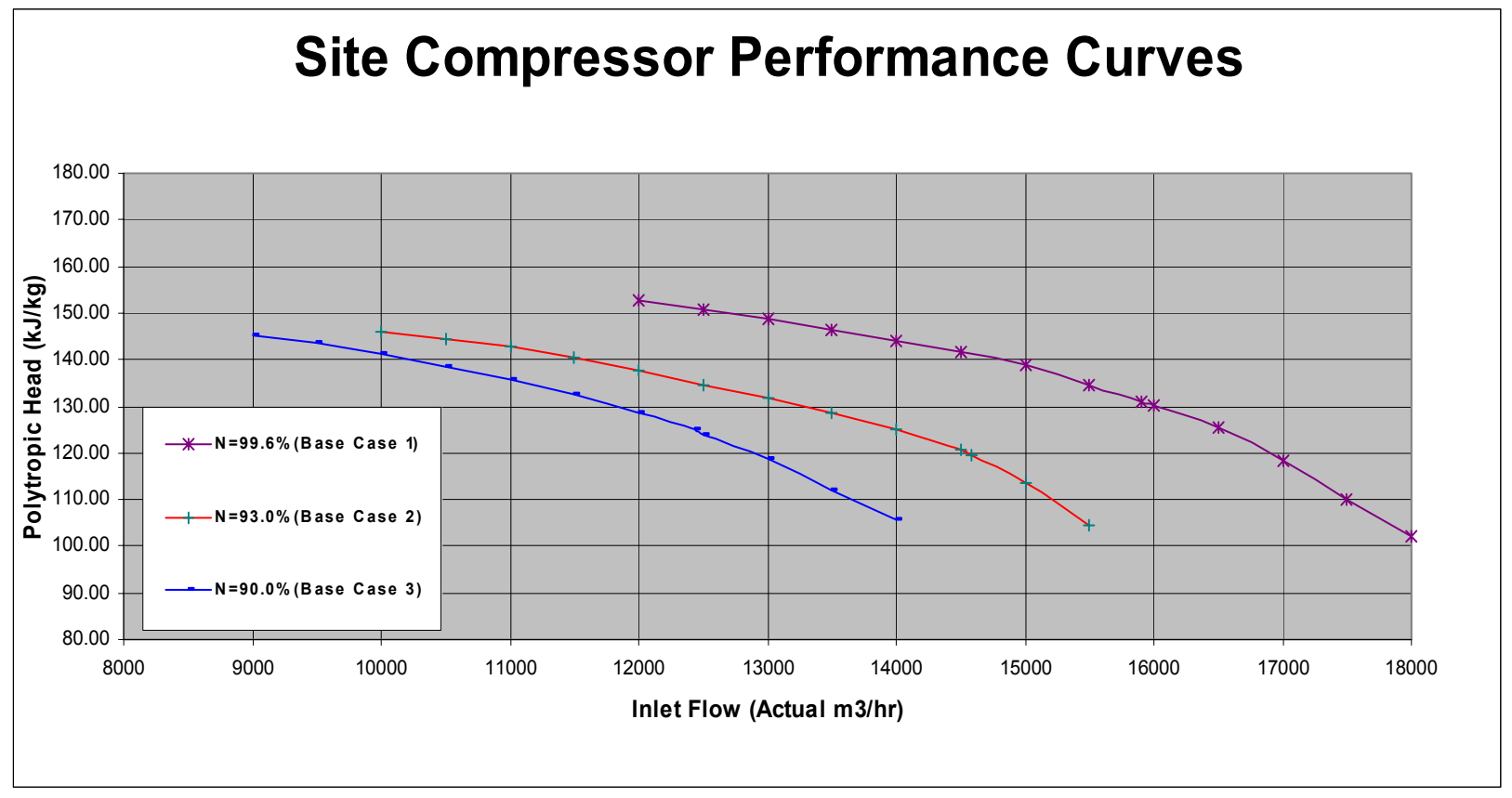

Figure 6. The generated Actual Site Compressor Performance Curves for 99.6\%, 93\% and 90\% RPMs

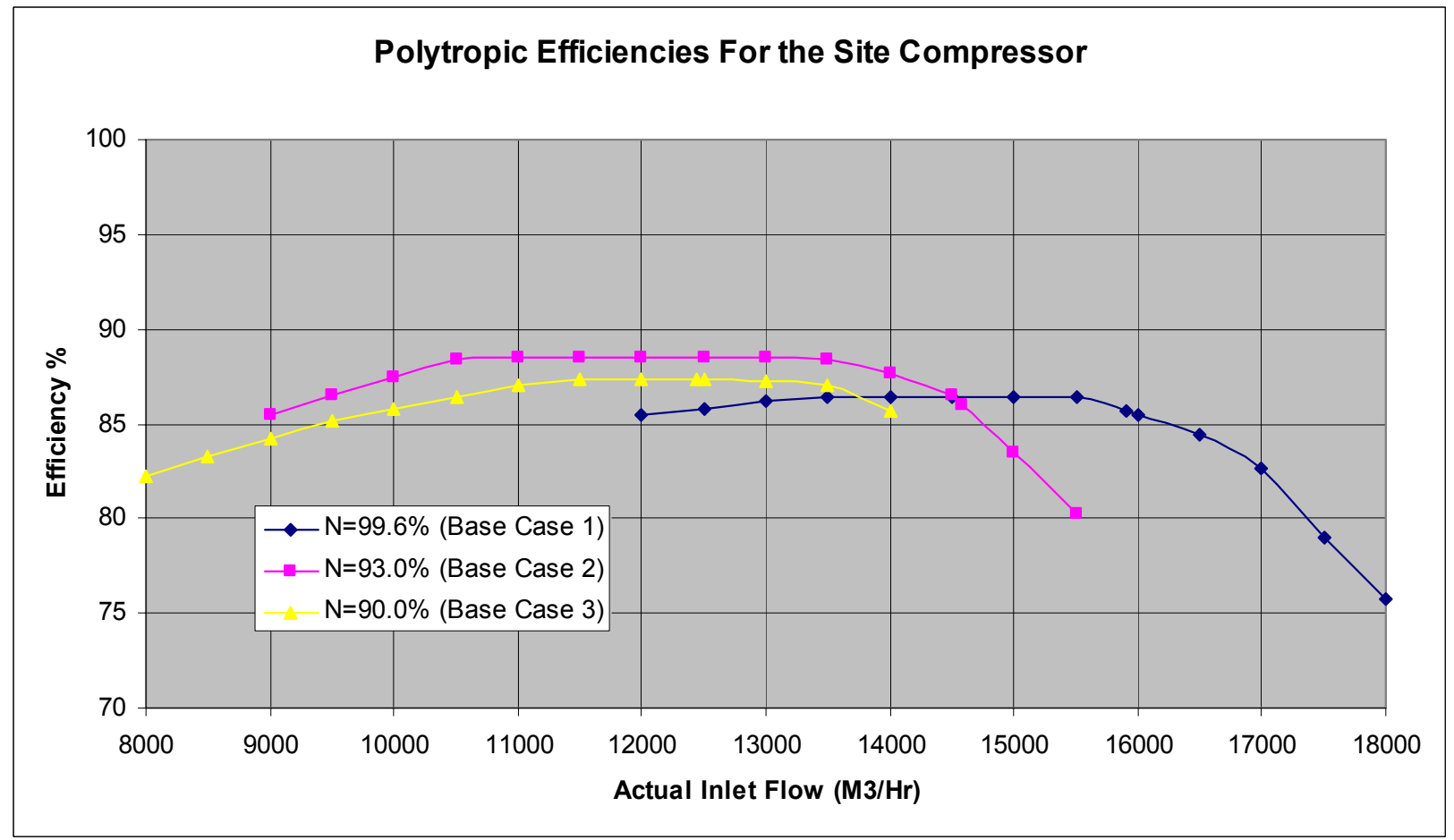

Figure 7. The generated Actual Site Compressor Polytropic Efficiencies for $99.6 \%, 93 \%$ and $90 \%$ RPMs. 


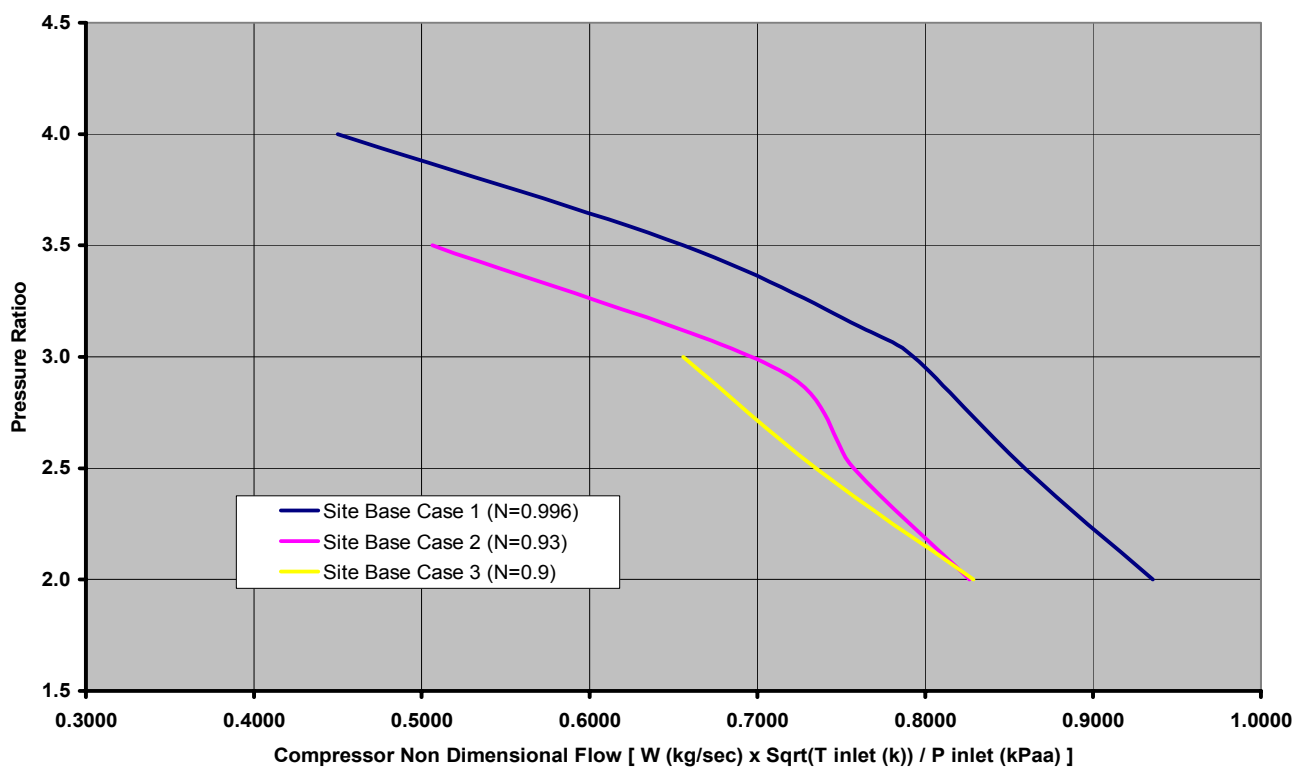

Figure 8. Pressure Ratio (PR) versus CNDF for the site compressor at various speeds

Table 1. The conditions of site compressor for the three base cases

\begin{tabular}{|l|c|c|c|c|}
\hline Parameter & Base Case 1 & Base Case 2 & Base Case 3 & Unit \\
\hline \multirow{3}{*}{ Flow rate } & 122.58 & 118.3 & 102.7 & MMScfd \\
\cline { 2 - 5 } & 150400 & 145000 & 126000 & $\mathrm{Kg} / \mathrm{hr}$ \\
\cline { 2 - 5 } & 15910 & 14580 & 12440 & Actual m3/hr \\
\hline Mol. Wt & 24.6 & 24.6 & 24.6 & $\mathrm{Kg} / \mathrm{kmol}$ \\
\hline Inlet Press & 9.7 & 9.9 & 9.7 & Bara \\
\hline Inlet Temp & 315.3 & 307.2 & 296.7 & $\mathrm{~K}^{\mathrm{o}}$ \\
\hline Outlet Press & 30.3 & 29.1 & 31.0 & Bara $^{\circ}$ \\
\hline Outlet Temp & 398.2 & 384.5 & 378.2 & $\mathrm{~K}^{\mathrm{o}}$ \\
\hline Speed & $99.6 \%$ & $93 \%$ & $90 \%$ & - \\
\hline
\end{tabular}

Table 2. Summary of Rated and Site Performance Data used for Adaptation

\begin{tabular}{|l|c|c|c|c|c|c|}
\hline Parameter & $\begin{array}{c}\text { Rated Performance } \\
\text { Data By } \\
\text { Manufacturer }\end{array}$ & $\begin{array}{c}\text { Base } \\
\text { Case 1 }\end{array}$ & $\begin{array}{c}\text { Rated Performance } \\
\text { Data By } \\
\text { Manufacturer }\end{array}$ & $\begin{array}{c}\text { Base Case } \\
2\end{array}$ & $\begin{array}{c}\text { Rated Performance } \\
\text { Data By } \\
\text { Manufacturer }\end{array}$ & $\begin{array}{c}\text { Base } \\
\text { Case 3 }\end{array}$ \\
\hline Rated (OEM) & Site & Rated (OEM) & Site & Rated (OEM) & Site \\
\hline Mol. Wt & 27.69 & 24.6 & 24.88 & 24.6 & 26.84 & 24.6 \\
\hline Inlet T /K & 316.3 & 315.3 & 303.9 & 307.2 & 297.1 & 296.7 \\
\hline Inlet P / Bara & 10.86 & 9.7 & 10.06 & 9.9 & 10.99 & 9.7 \\
\hline Sp. Ht. Ratio & 1.21 & 1.21 & 1.236 & 1.213 & 1.225 & 1.216 \\
\hline Suction Z & 0.952 & 0.962 & 0.960 & 0.958 & 0.943 & 0.9544 \\
\hline
\end{tabular}


Proceedings of the $13^{\text {th }}$ Int. AMME Conference, 27-29 May, 2008

\begin{tabular}{|l|l|}
\hline MP & 461 \\
\hline
\end{tabular}

Table 3. The Conditions At Which Predicted Performance Curves Are Available From OEM For The Site Comnressor

\begin{tabular}{|c|c|c|c|c|c|c|c|c|c|c|c|c|c|}
\hline $\begin{array}{l}\text { Case } \\
\text { Ref. }\end{array}$ & OEM & Time & MWt & Intake Press & Intake Temp & $\begin{array}{l}z @ \\
\text { Suction }\end{array}$ & $\mathrm{Cp} / \mathrm{Cv}_{\mathrm{v}}$ & & & SPEED & RPM CU & VES BY & EM \\
\hline No. & Case No. & & & Bara & C & & & A & B & C & D & E & $\mathbf{F}$ \\
\hline 1 & 1 & summer 04 & 27.24 & 11.31 & 45.3 & 0.953 & 1.213 & 9500 & 9048 & 8671 & 8142 & 7238 & 6333 \\
\hline 2 & 11 & summer 05 & 26.27 & 10.01 & 40.2 & 0.96 & 1.222 & 9500 & 9048 & 8824 & 8143 & 7238 & 6334 \\
\hline 3 & 3 & winter 04 & 25.71 & 10.42 & 17 & 0.949 & 1.239 & 9500 & 9048 & 8604 & 8142 & 7238 & 6333 \\
\hline 4 & 4 & summer 04 & 27.42 & 10.3 & 44.6 & 0.956 & 1.21 & 9500 & 9048 & 8526 & 8142 & 7238 & 6333 \\
\hline 5 & 5 & winter 11 & 24.59 & 9.43 & 6.1 & 0.952 & 1.251 & 9500 & 9048 & 8870 & 8142 & 7238 & 6333 \\
\hline 6 & 6 & winter 11 & 26.29 & 10.12 & 25.2 & 0.951 & 1.227 & 9500 & 9048 & 8523 & 8142 & 7238 & 6333 \\
\hline 7 & 7 & summer 04 & 27.57 & 11.06 & 47.4 & 0.953 & 1.209 & 9500 & 9048 & 8768 & 8142 & 7238 & 6333 \\
\hline 8 & 8 & summer 04 & 26.77 & 11.13 & 44.6 & 0.955 & 1.216 & 9500 & 9048 & 8671 & 8142 & 7238 & 6333 \\
\hline 9 & 9 & summer 04 & 27.52 & 11.1 & 46.7 & 0.953 & 1.21 & 9429 & 8980 & 8795 & 8081 & 7184 & 6285 \\
\hline 10 & 10 & summer 04 & 27.68 & 11.05 & 47.3 & 0.953 & 1.209 & 9492 & 9040 & 8763 & 8135 & 7232 & 6327 \\
\hline 11 & 11 & summer & 26.02 & 9.32 & 40.1 & 0.963 & 1.222 & 9500 & 9188 & 9048 & 8142 & 7238 & 6333 \\
\hline 12 & 11 & winter & 23.33 & 8.79 & 3.7 & 0.96 & 1.264 & 9500 & 9463 & 9048 & 8142 & 7238 & 6333 \\
\hline 13 & 1 & summer 04 & 28.24 & 11.77 & 45.5 & 0.947 & 1.207 & 9500 & 9048 & 8180 & 7238 & 6334 & \\
\hline 14 & 2 & winter 04 & 25.18 & 10.28 & 19.4 & 0.954 & 1.243 & 9500 & 9048 & 8677 & 8143 & 7238 & 6334 \\
\hline 15 & 3 & winter 04 & 26.92 & 11.1 & 20.5 & 0.941 & 1.23 & 9500 & 9048 & 8180 & 7238 & 6334 & \\
\hline 16 & 4 & summer 11 & 27.69 & 10.86 & 43.1 & 0.952 & 1.21 & 9500 & 9048 & 8224 & 7238 & 6334 & \\
\hline 17 & 5 & winter 11 & 24.88 & 10.06 & 30.7 & 0.96 & 1.236 & 9500 & 9048 & 8936 & 8143 & 7238 & 6334 \\
\hline 18 & 6 & winter 11 & 26.84 & 10.99 & 23.9 & 0.943 & 1.225 & 9500 & 9048 & 8143 & 8033 & 7238 & 6334 \\
\hline 19 & 7 & summer 04 & 28.26 & 11.75 & 45.5 & 0.947 & 1.207 & 9500 & 9048 & 8210 & 7238 & 6334 & \\
\hline 20 & 8 & summer 04 & 28.15 & 11.8 & 45.4 & 0.947 & 1.208 & 9500 & 9048 & 8208 & 7238 & 6334 & \\
\hline 21 & 9 & summer 04 & 26.92 & 11.79 & 47 & 0.953 & 1.215 & 9500 & 9048 & 8349 & 8143 & 7238 & 6334 \\
\hline 22 & 10 & summer 04 & 28.24 & 11.77 & 45.4 & 0.947 & 1.207 & 9500 & 9048 & 8208 & 7238 & 6334 & \\
\hline 23 & 11 & winter & 23.48 & 9.4 & 4.1 & 0.957 & 1.264 & 9500 & 9135 & 9048 & 8143 & 7238 & 6334 \\
\hline
\end{tabular}


Table 4. Sample Exact Performance matching - Site Base Case 1- By applying HYSYS. Scale Factor $(\mathrm{SF}=0.915)$ is derived through the polytropic head obtained from HYSYS for exact site match (130.9 $\mathrm{kJ} / \mathrm{kg}$ ) by the expected value obtained from modification of supplier data $(143.1 \mathrm{~kJ} / \mathrm{kg})$. This $\mathrm{SF}$ is then applied to the expected performance column.

\begin{tabular}{|l|c|c|c|c|}
\hline Inlet Flow & \multicolumn{2}{|c|}{ Polytropic Head @ 9500 rpm } & Polytropic Head @ 9462 rpm & $\begin{array}{c}\text { Polytropic Head @ 9462 rpm } \\
\text { By HYSYS }\end{array}$ \\
\hline Act M3/Hr & (Rated, NP) kJ/kg & (Corrected) kJ/kg & $\mathrm{kJ} / \mathrm{kg}$ & $\mathrm{kJ} / \mathrm{kg}$ \\
\hline 12000 & 148.5 & 168.51 & 167.17 & 152.92 \\
12500 & 146.5 & 166.24 & 164.91 & 150.86 \\
13000 & 144.5 & 163.97 & 162.66 & 148.80 \\
13500 & 142 & 161.14 & 159.85 & 146.22 \\
14000 & 140 & 158.87 & 157.60 & 144.16 \\
14500 & 137.5 & 156.03 & 154.78 & 141.59 \\
15000 & 134.7 & 152.85 & 151.63 & 138.71 \\
15500 & 130.5 & 148.09 & 146.90 & 134.38 \\
15910 & 127.119 & 144.25 & 143.10 & 130.90 \\
16000 & 126.3 & 143.32 & 142.18 & 130.06 \\
16500 & 121.8 & 138.21 & 137.11 & 125.42 \\
17000 & 115 & 130.50 & 129.46 & 118.42 \\
17500 & 107 & 121.42 & 120.45 & 110.18 \\
18000 & 99 & 112.34 & 111.44 & 101.94 \\
\hline
\end{tabular}

Table 5. Off-Design Performance comparison between default map and site measured values for the test compressor

\begin{tabular}{|c|c||c|c|c|c|}
\hline \multirow{2}{*}{ No } & Parameter & Base Case & $\begin{array}{c}\text { Value Before } \\
\text { Adaptation } \\
\text { (Default Map) }\end{array}$ & $\begin{array}{c}\text { Value Measured } \\
\text { (At Site) }\end{array}$ & Error \% \\
\hline \hline \multirow{2}{*}{1} & \multirow{2}{*}{$\mathrm{N}$} & 1 & \multicolumn{2}{|c|}{0.996} & 0 \\
\cline { 3 - 6 } & & 2 & \multicolumn{2}{|c|}{0.93} & 0 \\
\cline { 3 - 6 } & \multirow{2}{*}{ Pout } & 3 & \multicolumn{2}{|c|}{0.90} & 0 \\
\hline & & 2 & 26.38 & 29.1 & -9.3 \\
\cline { 3 - 6 } & \multirow{2}{*}{3} & 3 & 28.70 & 31.0 & -7.4 \\
\hline \multirow{2}{*}{3} & \multirow{2}{*}{ Tout } & 1 & 133.5 & 125.0 & +6.8 \\
\cline { 3 - 6 } & & 2 & 105.6 & 111.3 & -5.1 \\
\cline { 3 - 6 } & & 3 & 100.5 & 105.0 & -4.3 \\
\hline
\end{tabular}

Table 6. The error (objective function) between measured values and the corresponding values after adaptation using HYSYS 


\begin{tabular}{|c|c|c|c|c|c|}
\hline \hline \multirow{2}{*}{ No } & Parameter & Base Case & $\begin{array}{c}\text { Value } \\
\text { Measured }\end{array}$ & $\begin{array}{c}\text { Value After } \\
\text { Adaptation }\end{array}$ & Error \% \\
\hline \hline \multirow{2}{*}{1} & \multirow{2}{*}{$\mathrm{N}$} & 1 & \multicolumn{2}{|c|}{0.996} & 0 \\
\cline { 3 - 6 } & & 2 & \multicolumn{2}{|c|}{0.93} & 0 \\
\cline { 3 - 6 } & \multirow{2}{*}{2} & 3 & \multicolumn{2}{|c|}{0.90} & 0 \\
\hline \hline \multirow{2}{*}{3} & \multirow{2}{*}{3} & 2 & 30.3 & 30.3 & 0.0 \\
\cline { 3 - 6 } & \multirow{2}{*}{ Tout, $^{\circ} \mathrm{K}$} & 3 & 31.0 & 31.0 & 0.0 \\
\cline { 3 - 6 } & & 2 & 398.2 & 398.2 & 0.0 \\
\cline { 3 - 6 } & & 3 & 384.5 & 384.5 & 0.0 \\
\hline & & 2 & 378.2 & 37.2 & 0.0 \\
\hline
\end{tabular}

Table 7. Compressor Non-Dimensional Flow derived from HYSYS for the site base cases

\begin{tabular}{|c|c|c|c|c|c|c|c|c|c|c|}
\hline \multirow[t]{2}{*}{$\begin{array}{l}\text { Base } \\
\text { Case }\end{array}$} & \multicolumn{2}{|c|}{ RPM } & \multirow{2}{*}{$\begin{array}{l}\mathrm{P}(\text { Inlet }) \\
\text { (Bara) }\end{array}$} & \multirow[t]{2}{*}{ PR } & \multirow{2}{*}{$\begin{array}{l}\mathrm{P} \text { (Outlet) } \\
\text { (Bara) }\end{array}$} & \multirow{2}{*}{$\frac{\mathrm{W} \times 10^{\wedge} 5}{(\mathrm{~kg} / \mathrm{hr})}$} & \multirow{2}{*}{$\begin{array}{l}\mathrm{W} \\
(\mathrm{Kg} / \mathrm{Sec})\end{array}$} & \multirow{2}{*}{$\begin{array}{c}\begin{array}{c}\text { Inlet } \\
\text { Temp }\end{array} \\
\mathrm{K} \\
\end{array}$} & \multirow{2}{*}{$\begin{array}{c}\begin{array}{c}\text { Outlet } \\
\text { Temp }\end{array} \\
\mathrm{K} \\
\end{array}$} & \multirow[t]{2}{*}{ CNDF } \\
\hline & $\%$ & Value & & & & & & & & \\
\hline \multirow[t]{6}{*}{1} & 99.6 & 9462 & 9.7 & 2 & 20.4 & 1.84 & 51.11 & 315.25 & 377.75 & 0.6353 \\
\hline & 99.6 & 9462 & 9.7 & 2.5 & 25.3 & 1.69 & 46.94 & 315.25 & 388.35 & 0.5245 \\
\hline & 99.6 & 9462 & 9.7 & 3 & 30.1 & 1.56 & 43.33 & 315.25 & 395.95 & 0.4434 \\
\hline & 99.6 & 9462 & 9.7 & 3.12 & 31.3 & 1.504 & 41.78 & 315.25 & 398.15 & 0.4195 \\
\hline & 99.6 & 9462 & 9.7 & 3.5 & 35.0 & 1.29 & 35.83 & 315.25 & 406.35 & 0.3403 \\
\hline & 99.6 & 9462 & 9.7 & 4 & 39.8 & 0.885 & 24.58 & 315.25 & 419.75 & 0.2187 \\
\hline \multirow[t]{4}{*}{2} & 93.0 & 8835 & 9.9 & 2 & 20.8 & 1.68 & 46.67 & 307.15 & 368.95 & 0.5670 \\
\hline & 93.0 & 8835 & 9.9 & 2.5 & 25.8 & 1.54 & 42.78 & 307.15 & 379.45 & 0.4672 \\
\hline & 93.0 & 8835 & 9.9 & 2.94 & 30.1 & 1.45 & 40.28 & 307.15 & 386.45 & 0.4068 \\
\hline & 93.0 & 8835 & 9.9 & 3.5 & 35.7 & 1.03 & 28.61 & 307.15 & 398.15 & 0.2655 \\
\hline \multirow[t]{5}{*}{3} & 90.0 & 8550 & 9.7 & 2 & 20.4 & 1.68 & 46.67 & 296.65 & 348.45 & 0.5627 \\
\hline & 90.0 & 8550 & 9.7 & 2.5 & 25.3 & 1.49 & 41.39 & 296.65 & 362.45 & 0.4486 \\
\hline & 90.0 & 8550 & 9.7 & 3 & 30.1 & 1.33 & 36.94 & 296.65 & 373.45 & 0.3667 \\
\hline & 90.0 & 8550 & 9.7 & 3.2 & 32.0 & 1.26 & 35.00 & 296.65 & 378.15 & 0.3367 \\
\hline & 90.0 & 8550 & 9.7 & 3.5 & 35.0 & 1.11 & 30.83 & 296.65 & 385.45 & 0.2840 \\
\hline
\end{tabular}

